\title{
THE INHERITANCE AND EXPRESSION OF UNILATERAL INCOMPATIBILITY IN SOLANUM *
}

\author{
PAUL GRUN and MARY AUBERTIN \\ Department of Botany,* The Pennsylvania State University, \\ University Park, Pennsylvania
}

Received 28.vi.65

\section{INTRODUCTION}

A substantial body of evidence exists showing that the cross of selfincompatible pistillate parent by self-compatible staminate parent of a number of genera fails while the reciprocal succeeds. The phenomenon, termed unilateral incompatibility, has been demonstrated in crosses between species of Nicotiana (Anderson and DeWinton, 1931), Petunia (Mather, 1943), Lycopersicon (McGuire and Rick, 1954; Martin, 1961a, 1961 $b, 1963$ ), Antirrhinum (Harrison and Darby, 1955), and Solanum (Garde, 1959; Grun and Radlow, I961; Pandey, 1962). One mechanism that leads to unilateral incompatibility operates through an inhibition of growth of self-compatible pollen tubes down selfincompatible styler tissue. It has been demonstrated (Lewis and Crowe, 1958) that this mechanism can operate even in crosses between members of separate genera and families.

Since, therefore, unilateral incompatibility has been long established in a diverse spectrum of genera, the details of its genetic basis and mechanism of action are of interest in interpreting its role in plant evolution. The phenomenon plays a major role as an internal isolating mechanism in the genus Solanum. Self-compatible $S$. verrucosum pollen growth is inhibited on some self-incompatible clones of $S$. chacoense, kurtzianum, tarijense, tuberosum Groups Phureja and Stenotomum, soukupii, simplicifolium, neohawkesii, sparsipilum, vernei, cardiophyllum, ehrenbergii, jamesii, pinnatisectum and megistacrolobatum (Garde, I959; Grun and Radlow, $196 \mathrm{r}$; Pandey, 1962) while the pollen tube growth of the reciprocal crosses is not inhibited. Growth of self-compatible $S$. brevidens pollen tubes is inhibited on styles of eight self-incompatible species while the reciprocal pollen tubes grow normally (Pandey, 1962).

It was shown in earlier studies that self-incompatible biotypes of S. chacoense, S. soukupii (Grun and Radlow, 196I) and $S$. vernei (Pandey, 1962) included clones that did not show unilateral incompatibility when crossed with self-compatible $S$. verrucosum. The present report analyses two questions concerning this material: ( 1 ) What is the genic basis for the difference between self-incompatible clones that show

* Authorised for publication on $15^{\text {th }}$ June 1965 as paper No. 3026 in the Journal Series of the Pennsylvania Agricultural Experiment Station and Contribution No. 325 from the Department of Botany. 
unilateral incompatibility and those that do not? (2) At what stage in growth of the pollen tubes is the unilateral incompatibility expressed?

\section{MATERIALS AND METHODS}

Diploid species of Solanum of the section Tuberarium were used. Their identities and places of origin are listed in table $\mathrm{I}$. To test crossability, flowers of the pistillate parent were emasculated at a late bud stage, allowed to open inside a cheesecloth bag, pollinated with fresh pollen and then protected from insects by re-covering with the cheesecloth bag. Records were kept of the number of cross attempts and berries set. All the clones used in this study to analyse cross-compatibility with self-compatible $S$. verrucosum pollen were themselves self-incompatible. In order to avoid confusion that might arise from two uses of the word " compatible ", a plant having styles compatible to $S$. verrucosum pollen will be referred to as an " acceptor", and one not compatible as a " non-acceptor". Classification required a method for

TABLE I

Identity and place of origin of clones used

\begin{tabular}{|c|c|c|c|}
\hline Species & & PI numbers & Place of origin \\
\hline S. chacoense . & . & $\begin{array}{l}23058 \mathrm{I}(\mathrm{T}) \\
133073(\mathrm{AA}), 133664(\mathrm{AC}) \\
189217(\mathrm{CA}), 189218(\mathrm{CF}) \\
133709(\mathrm{CI})\end{array}$ & $\begin{array}{l}\text { Unknown } \\
\text { Central Argentina } \\
\text { North-western Argentina }\end{array}$ \\
\hline S. soukupii & . & 218227 (CR-1) & Southern Peru \\
\hline S. simplicifolium & . & $208866(\mathrm{CK})$ & North-western Argentina \\
\hline
\end{tabular}

determining how many individual pollinations must fail to lead to berry set before a plant could safely be classified as non-acceptor. The acceptor parents used were clones of $S$. soukupii (CR-1) and $S$. chacoense (T and AC). The ratio of berries set per cross attempted when $S$. verrucosum pollen was used on styles of each of these clones was reported earlier (Grun and Radlow, 1961). The method used in this study consisted of determining the exponential to which the proportionate failure of berry set must be raised to reduce that probability of complete berry set failure to less than 1 per cent. Thus, 8 berries were set of 18 cross attempts when $S$. verrucosum self-compatible pollen was put on styles of $S$. chacoense clone T. This meant that 10 , or 55 per cent., of the cross attempts failed. It would require 8 separate trials each of which had a 55 per cent. likelihood of failure to reduce the likelihood of total failure to observe a berry set to 1 per cent. since $0.55^{8}$ is less than 0.01 . It was calculated that, on this basis, $S$. soukupii clone CR-1 required 7 separate trials and $S$. chacoense clone AC required 17 separate trials. Progeny of each acceptor were classified as non-acceptors only after the minimum number of pollinations calculated for the acceptor parent had been performed. In most cases 20 separate pollinations were performed. When berries were produced they were cut open to verify their seed content.

Growth of pollen tubes was observed by use of the fluorescent stain procedure developed by Martin (1959). S. verrucosum pollen was put on styles of flowers on plants in the greenhouse and styles were fixed $4^{8}$ hours after pollination. Each pollination for this purpose was routinely done on at least 3 flowers per cross. The pollen tubes were examined with a Leitz Ortholux microscope using dark field illumination. The light from a Xenon discharge tube XBO 162 was passed through a dark filter ( $4 \mathrm{~mm} \mathrm{BG}_{12}$ ) to screen out most of the wave lengths of visible light. 


\section{RESULTS}

(i) Inheritance of acceptance and non-acceptance

The initial step consisted of analysis of reciprocal $F_{1}$ hybrids between acceptor and non-acceptor clones (table 2). While one population of

TABLE 2

Acceptance of $F_{1}$ hybrids following the cross acceptor $\times$ non-acceptor and its reciprocal

\begin{tabular}{|c|c|c|c|}
\hline \multicolumn{2}{|c|}{ Parents } & \multicolumn{2}{|c|}{ Progeny } \\
\hline Pistillate & Staminate & Acceptors & Non-acceptors \\
\hline $\begin{array}{l}\text { 1. S. soukupii (CR-1)* } \\
\text { 2. Reciprocal } \\
\text { 3. S. chacoonse (T)* } \\
\text { 4. Reciprocal } \\
\text { 5. S. chacoense (AC)* } \\
\text { 6. Reciprocal } \\
\text { 7. S. chacoense (AC)* } \\
\text { 8. Reciprocal } \\
\text { 9. S. chacoense (AA)* } \\
\text { 10. Reciprocal }\end{array}$ & $\begin{array}{l}\text { S. simplicifolium }(\mathrm{CK}) \dagger \\
\text { S. chacoense }(\mathrm{CF}) \dagger \\
\text { S. chacoense }(\mathrm{CI}) \dagger \\
\text { S. chacoense }(\mathrm{CA}) \dagger \\
\text { S. chacoense }(\mathrm{CF}) \dagger\end{array}$ & $\begin{array}{l}0 \\
0 \\
1 \\
1 \\
4 \\
7 \\
1 \\
2 \\
2 \\
1\end{array}$ & $\begin{array}{r}12 \\
5 \\
6 \\
11 \\
4 \\
1 \\
3 \\
3 \\
1 \\
7\end{array}$ \\
\hline
\end{tabular}

* Acceptor parent.

$\dagger$ Non-acceptor parent.

the cross produced only non-acceptors, the others showed $F_{1}$ segregation of acceptors and non-acceptors. These facts indicated that nonacceptance is probably dominant, and that it is likely that most of the

TABLE 3

Acceptance of progeny following the cross acceptor $\times$ acceptor and non-acceptor $\times$ non-acceptor sibs among progeny plants of table 2

\begin{tabular}{|c|c|c|c|}
\hline \multirow{2}{*}{ Parents } & & \multicolumn{2}{|c|}{ Progeny } \\
\hline & & Acceptors & Non-acceptors \\
\hline $\begin{array}{l}\text { Acceptor progeny of Cross } 5 \text {. } \\
\text { Acceptor progeny of Crosses } 9 \text { and ro } \\
\text { Non-acceptor progeny of Cross } 3 \text {. } \\
\text { Non-acceptor progeny of Crosses } 3 \text { and } 4 \\
\text { Non-acceptor progeny of Crosses } 1 \text { and } 2 .\end{array}$ & 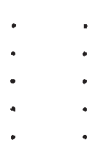 & $\begin{array}{r}12 \\
9 \\
2 \\
2 \\
0\end{array}$ & $\begin{array}{r}0 \\
9 \\
24 \\
7 \\
1\end{array}$ \\
\hline
\end{tabular}

non-accepting parents used were heterozygous for one or more genes for non-acceptance. Results of the reciprocal crossings were similar so it was apparent that cytoplasmic factors did not play a role in the phenomenon. Population sizes were small, and therefore the $F_{1}$ data were not used in an attempt at a factorial interpretation.

Since the population sizes were small, and only one did show dominance of non-acceptance, the second step in analysis consisted of 
using acceptor and non-acceptor progeny from the crosses listed in table 2 to produce hybrids acceptor $\times$ acceptor and non-acceptor $\times$ nonacceptor. The assumption was made that if acceptors were recessive, the acceptor $\times$ acceptor progeny should produce non-segregating acceptor offspring, while the non-acceptor $\times$ non-acceptor populations would segregate. The prediction was only partially fulfilled (table 3 ). Progeny of Cross 5 of table 2 seemed to confirm that acceptance was recessive, while those of Crosses 9 and ro showed that acceptor parents could produce non-acceptor progeny. A possible explanation for this result is that one of the acceptor plants of this cross was a misclassification. This could have happened if a non-acceptor plant occasionally accepted self-compatible pollen in a manner analogous to

TABLE 4

Acceptance of progeny following the backcross of non-acceptor $F_{1}$ and the acceptor parent

\begin{tabular}{|c|c|c|c|c|c|}
\hline \multirow{2}{*}{ Cross } & \multirow{2}{*}{$F_{1}$} & \multicolumn{4}{|c|}{ Progeny } \\
\hline & & $\begin{array}{l}\text { Recurrent } \\
\text { acceptor }\end{array}$ & Acceptors & $\begin{array}{c}\text { Non- } \\
\text { acceptors }\end{array}$ & Ratio \\
\hline \multirow{9}{*}{$\begin{array}{l}1 \\
2 \\
3 \\
4 \\
5 \\
6 \\
7 \\
8\end{array}$} & S. soukupii (GR-1) $\times$ simplicifolium (GK) & soukupii (CR-1) & I & 27 & $(1: 15)$ \\
\hline & S. chacoense $(\mathrm{T}) \times$ chacoense $(\mathrm{GF})$ & chacoense $(\mathrm{T})$ & 8 & 21 & $1: 3$ \\
\hline & Sib of cross 2 & chacoense ( $\mathrm{T})$ & 1 & 5 & $(1: 3)$ \\
\hline & S. chacoense $(\mathrm{AC}) \times$ chacoense $(\mathrm{CI})$. & chacoense (AC) & 7 & 21 & $1: 3$ \\
\hline & Sib of cross 4 & chacoense (AC) & 4 & 12 & $1: 3$ \\
\hline & S. chacoense (CI) $\times$ chacoense (AC) . & chacoense (AC) & 4 & 27 & $1: 3$ \\
\hline & Sib of cross 6 & $\begin{array}{l}\text { chacoense (AC) } \\
\text { chacoense (AC) }\end{array}$ & $\begin{array}{l}5 \\
4\end{array}$ & $\begin{array}{r}26 \\
8\end{array}$ & $\begin{array}{l}1: 3 \\
1: 3\end{array}$ \\
\hline & Total crosses 2-3 & $\ldots$ & 9 & 26 & $1: 3$ \\
\hline & Total crosses $4-8$ & $\cdots$ & 24 & 94 & $1: 3$ \\
\hline
\end{tabular}

the occasional berry set following self-pollination that can result from pseudocompatibility. The progeny of non-acceptor $\times$ non-acceptor showed segregation with the preponderance of non-acceptor plants to be expected if non-acceptance is dominant.

Back-cross progeny of the type (acceptor $\times$ non-acceptor) $\times$ (acceptor) were produced and tested (table 4). The ratios indicated fit the data with $P$ values of $0 \cdot 1$ or better. (Ratios indicated in parentheses were based on too few data to justify chi-square calculations.) The sum of crosses $4-8$ and 2-3 were calculated after the determination that there was no significant heterogeneity in the populations concerned.

The principal ratio observed of I acceptor:3 non-acceptors in these back-cross progenies could be interpreted as evidence that the nonacceptor parents contained two dominant genes either of which conditioned non-acceptance, while the acceptor was homozygous 
recessive for the two. Cross I would not fit the two-gene pattern, and presumably the ratio observed reflected the presence in the $S$. simplicifolium parent of more than two dominant genes that conditioned non-acceptance.

\section{(ii) Mechanism of non-acceptance}

Growth of pollen tubes of $S$. verrucosum self-compatible pollen down styles of acceptor and non-acceptor plants was followed by observing the orange colour of fluorescing tubes against the dark background of stylar tissue. Vascular strands in the stylar tissue also fluoresced orange, but their lighter fluorescence and general size and shape could be distinguished from the pollen tubes. Pollen germination was high and hundreds of tubes could be seen in the stigmatic area 24 and 36 hours after pollination. They were still clearly visible 48 hours after pollination and observations were made then to ensure sufficient time for growth down the styles.

Growth of $S$. verrucosum pollen tubes down styles of acceptor and non-acceptor plants is listed in table 5. A plus in the table indicates

TABLE 5

Growth of S. verrucosum self-compatible pollen tubes down styles of acceptor and non-acceptor plants

\begin{tabular}{|lr|c|c|c|c|}
\hline Type plant & $\begin{array}{c}\text { Number of } \\
\text { plants }\end{array}$ & \multicolumn{3}{|c|}{ Pollen tube growth } \\
\cline { 3 - 5 } & & + & - & + and $-*$ \\
\hline Acceptors & $\cdot$ & 17 & 14 & 2 & 1 \\
Non-acceptors &. & 29 & 12 & 12 & 5 \\
\hline
\end{tabular}

* Pollen tube growth varied in different tests.

growth of large numbers of pollen tubes all the way to the base of the style. A minus indicates that very few tubes went more than half-way down the style. In most cases such tubes progressed no further than one-tenth of the distance down the style. Classification of each plant was based on scoring of a minimum of six styles with pollen of at least two $S$. verrucosum testors.

Inhibition of pollen tube growth was more characteristic of the non-acceptors than acceptors suggesting that it is one of the mechanisms that conditioned non-acceptance. A few of the acceptor plants also showed failure of pollen tube growth. Apparently local conditions in styles of certain flowers were not favourable for tube development even following compatible pollinations. Approximately half of the nonacceptors showed pollen tube growth to the base of the style. In such plants non-acceptance resulted from the operation of a blockage of the 
male gametophyte in the ovary. The pollen tube growth data as a whole indicated, therefore, that non-acceptance can result from blockage of tube growth at two sites, one within the style and one in the ovary. It seems possible that the alternative sites of inhibition reflected difference in action of alternative non-acceptance genes.

\section{DISCUSSION}

Unilateral incompatibility has been widely observed associated with self-incompatibility. This association has lead to a concept expressed by Lewis and Crowe (1958) that the self-incompatibility allele itself has a dual role: Each self-incompatibility (SI) allele is known to have a highly specific inhibitory capacity such that it inhibits growth of pollen tubes down stylar tissue of its own kind. At the same time, all self-incompatibility alleles are visualised as sharing the capacity to inhibit growth down stylar tissue of pollen tubes bearing the allele for self-compatibility (SC).

The bulk of evidence cited for the two-fold role of the SI alleles has consisted of demonstration that in many cases the cross selfincompatible $\times$ self-compatible failed due to pollen tube inhibition. This evidence does not, however, relate unilateral incompatibility specifically to the SI alleles and self-incompatible plants could also have non-acceptor genes which could operate to inhibit growth of SC pollen tubes. The weight of evidence from studies carried out since formulation of the dual role concept suggests that unilateral incompatibility can be better explained in terms of inhibition of the growth of selfcompatible pollen tubes as a function of such non-acceptor genes.

The following examples in addition to the present study appear to be exceptions to the dual role concept of unilateral incompatibility: (I) There exist examples of self-incompatible biotypes of Nicotiana alata (Anderson and DeWinton, I93I), Solanum chacoense and S. soukupii (Grun and Radlow, I96I) and S. vernei (Pandey, I962) that act as acceptors of self-compatible pollen. (2) A self-incompatible nonacceptor clone of $S$. vernei showed segregation of self-incompatible progeny some of which were non-acceptors and some acceptors (Garde, I 959). (3) $F_{1}$ 's of Lycopersicon esculentum $(\mathrm{SC}) \times L$. peruvianum (SI) were self-incompatible and yet they showed unilateral incompatibility such that their pollen would not grow down styles of $L$. peruvianum (McGuire and Rick, 1954). The result was interpreted as showing that the hybrids inherited a factor or factors from L. esculentum that made their pollen fail to grow in styles of $L$. peruvianum. Such factors cannot have been merely the $S_{f}$ allele of $L$. esculentum since each $F_{1}$ contained a selfincompatibility allele from the $L$. peruvianum parent which could normally have conditioned growth of pollen tubes down the styles of at least some of the $L$. peruvianum biotypes tested. (4) $L$. hirsutum and L. esculentum showed unilateral incompatibility at a number of different levels such that not only did the cross self-incompatible $\times$ selfcompatible fail, but in certain cases self-incompatible $\times$ self-incompatible 
and self-compatible $\times$ self-compatible failed unilaterally (Martin, $196 \mathrm{I} a$ and 1963$)$.

Examples also exist of self-compatible non-acceptor species that are unilaterally isolated from other self-compatible species, but are not unilaterally isolated from certain self-incompatibles. These include Lycium chinense (Lewis and Crowe, 1958), Antirrhinum majus (Harris and Darby, 1955), and Papaver alpinum (Faberge, 1944). These were interpreted by Lewis and Crowe (1958) as species that have only recently become self-compatible. Interpretation of this type of crossing behaviour on the basis of $\mathrm{S}$ allele action required that there exist a third form of gene, Sc, which conditioned self-compatibility but retained the capacity for non-acceptance of SG (self-compatible) pollen tubes.

To retain the dual role concept in the face of these exceptions would require that one assume that each change in behaviour results from a corresponding change of the $\mathrm{S}$ allele. Lewis and Crowe (1958) postulated a fourth type of $\mathbf{S}$ allele $\left(\mathbf{S c}^{\prime}\right)$ which combines selfcompatibility, acceptance, and ability to grow down self-incompatible styles. Plants of this type apparently have not yet been found. To explain the situation in Solanum would require a fifth type of $\mathrm{S}$ allele that conditions self-incompatibility, but has lost the capacity to inhibit $\mathrm{SC}$ pollen tubes. To explain the unilateral incompatibility in crosses of self-incompatible $\times$ self-incompatible in Lycopersicon (Martin, I96ra and ${ }_{1963}$ ) would require a sixth $S$ allele that conditions selfincompatibility but has attained an ability to inhibit self-incompatible pollen tubes. This could lead to a complicated series of assumptions of properties of the $\mathrm{S}$ alleles for which, at present, evidence is lacking.

The alternative view suggested here is that unilateral incompatibility results from the operation of alleles of independent genes that condition acceptance. Four conditions could be visualised with genetic make-up as follows:

\begin{tabular}{|c|c|c|}
\hline Type plant & Compatibility alleles & Acceptor genes \\
\hline $\begin{array}{l}\text { Self-incompatible non-acceptor } \\
\text { Self-compatible non-acceptor } \\
\text { Self-compatible acceptor } \\
\text { Self-incompatible acceptor }\end{array}$ & $\begin{array}{l}\mathrm{S}_{1} \ldots \mathrm{S}_{n} \\
\mathrm{~S}_{f} \\
\mathrm{~S}_{f} \\
\mathrm{~S}_{1} \ldots \mathrm{S}_{n}\end{array}$ & $\begin{array}{l}\text { Non-acceptor } \\
\text { Non-acceptor } \\
\text { Acceptor } \\
\text { Acceptor }\end{array}$ \\
\hline
\end{tabular}

According to this interpretation the non-acceptor genes in a style will result in inhibition of acceptor pollen tubes, while acceptor stylar tissue will not inhibit either acceptor or non-acceptor pollen tubes. Non-acceptor genes might be few in number, as was found in this study, or many or polygenic as was found in the Lycopersicon hirsutum material (Martin, $196 \mathrm{I} a$ ). 


\section{SUMMARY}

Some self-incompatible clones of $S$. chacoense and $S$. soukupii could be successfully crossed reciprocally with self-compatible $S$. verrucosum. Other clones showed unilateral incompatibility, the cross succeeding only when the self-compatible species was used as pistillate parent. Genetic analysis showed that self-incompatible clones having the unilateral crossing barrier contained 2-4 dominant genes any one of which could condition the barrier. Cytoplasmic factors did not play a determining role. At least two mechanisms lead to unilateral incompatibility, one expressed as inhibition of pollen tube growth in the upper half of the style and the other as a blockage that operated after pollen tubes had grown to the ovary. These data and others are used as a basis for an interpretation of unilateral incompatibility as conditioned by genes other than the self-incompatibility alleles themselves.

Acknowledgments.-We wish to express our sincere thanks to the Plant Introduction Station of the U.S. Department of Agriculture for supplying the plant material used in this study. The study was supported by a grant from the National Science Foundation (GI939I).

\section{REFERENCES}

ANDERSON, E., AND DEWINTON, D. 1931. The genetic analysis of an unusual relationship between self-sterility and self-fertility in Nicotiana. Annals Missouri Bot. Garden, $18,97-116$.

Faberge, A. c. 1944. Genetics of the Scapiflora section of Papaver. F. Genet., 46 , 125-149.

GARDE, N. M. 1959. Mechanisms of species isolation in tuberous Solanum. Agronomia Lusitana, 21, 19-42.

GRUN, P., AND RADLOW, A. I961. Evolution of barriers to crossing of self-incompatible with self-compatible species of Solanum. Heredity, 16, 137-143.

HARRISON, B. J., AND DARBY, L. A. I955. Unilateral hybridization. Nature, 176, 982. LEWIS, D., AND GROWE, L. K. 1958. Unilateral interspecific incompatibility in flowering plants. Heredity, 12, 233-256.

MARTIN, P. W. 1959. Staining and observing pollen tubes in the style by means of fluorescence. Stain Techn., 34, 125-128.

MARTIN, P. W. $196 \mathrm{I} a$. Complex unilateral hybridization in Lycopersicon hirsutum. Proc. Natl. Acad. Sci., 47, 855-857.

MARTIN, F. W. $196 \mathrm{I} b$. The inheritance of self-incompatibility in hybrids of Lycopersicon esculentum Mill. $\times L$. chilense Dun. Genetics, 46, 1443-1454.

MARTIN, F. W. 1963. Distribution and interrelationships of incompatibility barriers in the Lycopersicon hirsutum Humb. and Bonpl. Complex. Evolution, 17, 519-528.

MAther, K. 1943. Specific differences in Petunia. I. Incompatibility. F. Genet., 45, $215-235$.

MCGUIRE, D. C., AND RICK, C. M. 1954. Self-incompatibility in species of Lycopersicon sect. Eriopersicon and hybrids with $L$. esculentum. Hilgardia, 23, 101-124.

PANDEY, X. X. 1962. Interspecific incompatibility in Solanum species. Amer. Four. Bot., 49, 874-882. 